\title{
ROLE OF PARENT'S ATTRIBUTIONAL STYLE AND PARENT-CHILD RELATIONSHIP IN INCREASING SELF- ESTEEM OF CHILDREN WITH DYSLEXIA
}

\author{
Hilwa Abdullah @ Mohd. Nor ${ }^{1}$ \\ Faculty of Social Sciences and Humanities, Universiti Kebangsaan Malaysia (UKM), Malaysia. \\ (Email: hilwa@ukm.edu.my) \\ Diana Johan ${ }^{2}$ \\ Faculty of Social Sciences and Humanities, Universiti Kebangsaan Malaysia (UKM), Malaysia. \\ (Email: dianajhn25@gmail.com)
}

Received date: 11-08-2019

Revised date: $25-08-2019$

Accepted date: 27-08-2019

Published date: 15-09-2019

To cite this document: Hilwa, A. M. N., \& Johan, D. (2019). Role of Parent's Attributional Style and Parent-Child Relationship in Increasing Self-Esteem of Children with Dyslexia. International Journal of Education, Psychology and Counseling, 4 (32), 328-337.

DOI: $10.35631 /$ IJEPC.4320028

\begin{abstract}
Dyslexia is a specific learning disorder due to difficulties in phonological processing that impacts on the fluency and reading comprehension ability. The aim of this research is to identify the role of parents' attributional style and parent-child relationship in determining the level of self-esteem in children with dyslexia. There are 24 respondents who consist of the parent or the caregiver of children with dyslexia along with the child were invited to participate in this research. The method used in this research is a cross-sectional study design using a quantitative approach. The researcher used three different tests to measure the variables involved. Tests used in this research consist of Causal Dimensional Scale II, Parent-Child Relationship Inventory and Rosenberg's Self Esteem Scale. Results showed there is a significant relationship between parents' attributional style and level of self-esteem in children with dyslexia. Attributional style measured in this research consists of four dimensions namely, locus of causality, external control, stability, and personal control. However, only two of the dimensions mentioned above are significantly related to the level of self-esteem in children with dyslexia. The two dimensions are external control $(r=0.408, p>$ $0.05)$ and personal control $(r=0.557, p>0.05)$. Whereas, results showed there is no significant relationship between parent-child relationship and the level of self-esteem of children with dyslexia. In a nutshell, the role of parents' attributional style in determining the level of self-esteem in children with dyslexia is notably significant while the relationship of parent-child does not influence the level of self-esteem in children with dyslexia.
\end{abstract}

Keywords: Attributional Style, Parent - Child Relationship, Self-Esteem, Dyslexia 


\section{Introduction}

In Malaysia, neurodevelopmental disorder that occurs in childhood is quite familiar nowadays. Circumstances parents or teachers who are less savvy about this disorder is one of the reasons why a victim may face pressure. This happens when they blame themselves for things that are not in control of themselves. Based on figures in 2001 by the Ministry of Education, an estimated 290,000 children from 4.9 million children are likely to suffer from learning disorders such as dyslexia specifically categorized under neuro developmental disorder (MOE, 2000). According to the Diagnostic Statistic Manual of Mental Disorders 5th edition, the neurodevelopmental disorders are a group of conditions with onset in the developmental period. The disorders typically manifest early in development, often before the child enters grade school, and are characterized by developmental deficits that produce impairments of personal, social, academic, or occupational functioning. Delirium, confusion often starts in the early stages of development, frequently occurs before the child is learning in school and is characterized by the lack of progress that resulted in malfunction of personal, social, academic and work.

\section{Literature Review}

Dyslexia is detailed under specific learning disorders. Specific learning disorder is diagnosed when there is a lack of specifics in the ability of an individual to perceive or process information efficiently and accurately. The neuro developmental disorder first occurred during the years of formal schooling and learning difficulties characterized by a lasting deterioration in the form of academic skills such as reading, writing and / or arithmetic. Individual performance in related academic skills are below the normal level for age, or level of acceptable performance can only be achieved with great effort (DSM-V, 2013).

According to Rohaty (2005), the condition of dyslexia is not known due to the low level of awareness among the population of Malaysia (Noor Amiera et al., 2015). Knowledge and awareness of specific learning disorders is necessary so that parents and teachers are aware of the problems in dealing with children with dyslexia and eventually leads to seek an effective alternative to help the child. Children with dyslexia often associated with low levels of selfesteem. Self-esteem does not only involve subjective interpretation of someone's identity itself, but it also involves how this subjective interpretation is shaped by environment interaction (Anna et. al., 2014). In the study of Anna et. al. (2014), a young woman who suffered from dyslexia have a lower level of self-esteem compared with other groups of normal women. The low level of self-esteem can be seen as one aspect of emotional problems and other issues that correlate with dyslexia (Humphrey \& Mullins, 2002); only a few individuals who suffer from dyslexia see the challenge as a positive thing (Folb, 2013; Singer, 2005).

Although there are many previous studies on the skills of reading and reading problems of children, but little is known about what others think of the parents about the early development of children's reading and how the idea was changed after children start school (Natale et al., 2009). A conceptual framework to identify parents and how parents explain and evaluate the academic performance of children is attribution theory (Weiner, 1985, 1986, 1992) as used the study of Natale et al. (2009). According to Weiner $(1985,1986)$, attribution of causality varies according to three dimensions: locus (external-internal), stability (stableunstable), and control (controllable-uncontrollable) (Natale et al., 2009). Attribution can also be explained by how people perceive the cause of things. Previous studies focused style of attribution in dyslexic children compared with parents. 
In addition, the relationship between the parent-child was also associated with the level of self-esteem of dyslexic children. The negative impact on self-esteem in individuals who suffer from dyslexia may depend on the level of support at home (Anna et al., 2014). Heyman (2000) stated that healthy and stable social relations built by dyslexic children with their relatives help them to maintain a high level of self-esteem (Shehu et al., 2015). Parent-child relationship are played an important role in self-esteem of dyslexic children. Therefore, this study would focus on how the attribution of parents and parents-children relationship play an important role in improving the self-esteem of dyslexic children.

The purpose of this study was to identify the role of attribution style and parent - child relationship in increasing the self-esteem of children with dyslexia. Therefore, this study has outlined two major objectives as follows; identify the relationship between attribution style and self-esteem of parents of children with dyslexia and to identify the effects of parent child relationship and self-esteem of children with dyslexia.

\section{Methodology}

\section{Research Design and Participants}

The design used in this research was a cross-sectional study involved the use of questionnaire or survey form. The questionnaire was self-administered by researcher. Independent variables involved in this research includes parental attributional style and parent - child relationship whereas the dependent variable is the level of self-esteem among children with dyslexia.

The participants involved in this research were chosen from a specific population which consists of children with dyslexia. We targeted a group of 30 respondents among children with dyslexia along with their parent or caregiver respectively. However, only 26 sets of questionnaires were returned, and 2 sets of data were excluded and disregarded from data analysis. In this research, we have decided to use purposive sampling in recruiting the sample needed. In order to determine whether an individual is eligible to participate in this research, we decided to use the characteristics of parents or caregiver of children with dyslexia in Malaysia as a benchmark.

Since the sample needed in this research consists of a specific sample, we decided to use another sampling method which was snowball sampling to fulfil the requirement of this research. After a parent has given his consent to participate, the researcher then asked for help of the parent involved regarding the information of another participant. Using this method, the size of sample involved increased accordingly in line with the need of this research (Najib et. al., 2004). The participants were from two different location, which were from Sekolah Kebangsaan Taman Maluri, which provided a special class specifically for children with dyslexia. As for the snowball sampling method, the location was taken in Klang Valley according to the demographic background of participants involved.

\section{Measures}

In this study, there are three different psychological instruments used in order to measure all the variables involved. The questionnaire used in this study consists of 4 different sections namely, demographic section, section A, section B and section C. To measure parent's attributional style, Causal Dimensional Scale II was used (section A); Parent-Child Relationship Inventory (section B) was used to measure parent-child relationship and lastly, Rosenberg's Self-Esteem Scale (section C) was used to measure the level of self-esteem among children with dyslexia. 


\section{Causal Dimensional Scale II}

Causal Dimensional Scale II is the revised version and was developed by McAuley, Duncan and Russell (1992). This instrument is used to measure how an individual perceives causality of an event according to 4 different dimensions, locus of causality, external control, stability and personal control. This instrument has been modified according to the sample population involved in this study and it consists of 12 items in which the response will be rated in a 9point linear scale. Total score for each dimension is determined by the sum of items per dimension.

\section{Parent-Child Relationship Inventory}

This instrument was developed by Anthony B. Gerrard and it evaluates parent's attitude towards parenting as well as towards their children. It consists of 78 items and 7 content scales and one validity indicator. Content scales consist of 7 different dimensions namely, parental support, satisfaction with parenting, involvement, communication, limit setting, autonomy and role orientation. Whereas, for validity indicator, it only consists of one dimension namely social desirability. Content scale consists of 73 items in which 26 items are positively keyed-in while the rest of 47 items are negative. The rest of 5 items belong to social desirability dimension in which all of the items are negative. The higher the score in this dimension, the higher the level of social desirability of parents. This instrument uses a 4point Likert scale in which (1) represents strongly disagree, (2) disagree, (3) agree and (4) strongly agree. This instrument has also been translated into Malay language in order to fit the native language spoken by this research's sample.

\section{The Rosenberg Self-Esteem Scale (RSE)}

The Rosenberg Self-Esteem Scale Rosenberg (1965) is an attempt to achieve a unidimensional measure of global self-esteem. It was designed to be a Guttman scale, which means that the RSE items were to represent a continuum of self-worth statements ranging from statements that are endorsed even by individuals with low self-esteem to statements that are endorsed only by persons with high self-esteem. Rosenberg (1965) scored his 10-question scale that was presented with four response choices, ranging from a strongly agree to strongly disagree, as a six item Guttman scale. The first item included question 1 through 3 received a positive score if two or three of its questions were answered positively. Questions 4 and 5 and questions 9 and 10 were aggregated into two other items that were scored positively, if both questions in the item had positive answers. Question 6 through 8 counted individually formed the final three items. For the negatively worded RSE questions, responses that expressed disagreement and hence, were consistent with high self-esteem were considered positive. Rosenberg (1965) demonstrated that his scale was a Guttman scale by obtaining high enough reproducibility and scalability coefficients.

\section{Results}

Table 1 shows the demographic data of the participants in the study. Participants of the study consisted of 7 males (29.2\%) and 17 females (70.8\%), making it a total of 24 individuals. 14 of the respondents were mothers, 6 of them were fathers and the rest 4 of them were caretakers. $58.3 \%$ of the respondents possess a maternal relationship with the child, $25 \%$ of them possess a paternal relationship and $16.7 \%$ of them are the caretaker of the child. Meanwhile, based on their knowledge on dyslexia previously, this study reported a total of 17 participants that they do know about dyslexia before this and only 7 of them reported they do not know about dyslexia before this. From table 1, we can see that $70.8 \%$ of the participants knew about dyslexia before this and $29.2 \%$ of them reported that they do not possess 
knowledge about dyslexia before this. A total of 24 respondents are Malay. That makes a total of $100 \%$ of the respondents were Malay

Table 1: Demographic Data of the Participants

\begin{tabular}{lcc}
\hline Demographic & N & \% \\
\hline Sex & 7 & 29.2 \\
$\quad$ Male & 17 & 70.8 \\
$\quad$ Female & & \\
Relationship with child & 14 & 58.3 \\
$\quad$ Mother & 6 & 25.0 \\
$\quad$ Father & 4 & 16.7 \\
$\quad$ Caretaker & & 100 \\
Race & 24 & 70.8 \\
$\quad$ Malay & & 29.2 \\
$\quad$ Knowledge on dyslexia & 17 & \\
$\quad$ Yes & 7 & \\
$\quad$ No & & \\
\hline
\end{tabular}

Association Between Parent's Attributional Style and Level of Self-Esteem of Children with Dyslexia

Correlation is used to measure the linear association between two variables (Sabitha, 2006). Result of correlation between the two variables (attributional style and level of self-esteem in children with dyslexia) is shown in Table 2. Attributional style has 4 different dimensions; locus of causality, external control, stability and personal control. However, correlation analysis shows there is a significant association between two of the dimensions (external and personal control) with the level of self-esteem. Although the external control dimension has a small value of coefficient, it shows a significant association with the level of self-esteem in children $(\mathrm{r}=0.408, \mathrm{p}<0.05)$. The personal control dimension has a higher value of coefficient and shows a significant association with the level of self-esteem in children with dyslexia $(\mathrm{r}=0.557, \mathrm{p}<0.05)$.

Table 2: Correlation Between Parent's Attributional Style's Dimensions with Level of Self-Esteem of Children with Dyslexia

\begin{tabular}{llcccc}
\hline & & $\begin{array}{c}\text { Locus of } \\
\text { causality }\end{array}$ & External Control & Stability & $\begin{array}{c}\text { Personal } \\
\text { control }\end{array}$ \\
\hline Self-Esteem & Pearson Correlation & 0.131 & 0.408 & -0.319 & 0.557 \\
& Sig. (2-tailed) & 0.543 & 0.048 & 0.128 & 0.005 \\
& N & 24 & 24 & 24 & 24 \\
\hline
\end{tabular}

$\mathrm{p}<0.05$

Based on results obtained, it can be concluded that external control has an averagely strong association with the level of self-esteem in children with dyslexia whereas personal control has a stronger association with the level of self-esteem in children with dyslexia. Thus, hypothesis accepted. 
Relationship Between Parent's Attributional Style and Level of Self-Esteem in Children with Dyslexia

Table 3 shows result of multiple regression of external and personal control with level of selfesteem in children with dyslexia. Predictor value $\left(\mathrm{R}^{2}\right)$ of external control towards self-esteem is $0.166(\mathrm{R}=0.408)$. Changes in external control of attributional style will produce a change of $16.6 \%$ in level of self-esteem in children with dyslexia. On the other hand, personal control dimension shows a higher predictor value, $\mathrm{R}^{2}=0.363(\mathrm{R}=0.603)$. If there is any changes in personal control, it will produce a change of $36.3 \%$ in self-esteem of children with dyslexia.

Table 3: Multiple Regression Between Attributional Style and Self-Esteem in Children with Dyslexia

\begin{tabular}{lccc} 
Model & $\mathrm{R}$ & $\mathrm{R}^{2}$ & Adjusted R Square \\
\hline 1 (External) & $0.408^{\mathrm{a}}$ & 0.166 & 0.129 \\
2 (Personal) & $0.603^{\mathrm{b}}$ & 0.363 & 0.303 \\
\hline
\end{tabular}

a. Predictors: (Constant), External Control

b. Predictors: (Constant), External Control, Personal Control

Based on the results above, it can be concluded personal control dimension of parent's attributional style has a stronger relationship with level of self-esteem in children with dyslexia compared to external control dimension. This simply means that parents attributed the cause of their child's dyslexia to something more personal. Thus, alternative hypothesis accepted.

Association Between Dimensions of Parent-Child Relationship (Parental Support, Satisfaction with Parenting and Involvement) With Level of Self-Esteem in Children with Dyslexia

A Pearson correlation analysis was carried out to identify the association of dimensions in parent-child relationship with self-esteem of children with dyslexia. Referring to Table 4, result shows no significant association between the dimension of parental support and selfesteem of children with dyslexia $(r=0.150, p>0.05)$. Result shows there is no significant association between satisfaction with parenting and self-esteem in children with dyslexia $(\mathrm{r}=$ $0.111, \mathrm{p}>0.05)$. There is no significant association between involvement and self-esteem in children with dyslexia $(\mathrm{r}=0.257, \mathrm{p}>0.05)$.

Table 4: Correlation Between Parental Support, Satisfaction with Parenting And Involvement and Self-Esteem in Children with Dyslexia

\begin{tabular}{lc}
\hline Correlation & Self-Esteem \\
\hline Parental Support & 0.150 \\
Satisfaction with parenting & 0.111 \\
Involvement & 0.257 \\
\hline
\end{tabular}




\section{Discussion \& Conclusion}

Results showed that there are two dimensions in the style of attribution of parents who have a significant relationship with self-esteem of dyslexic children. External control dimension has a significant relationship with self-esteem of dyslexic children with $r=0408$. This shows that a simple relationship between external control and self-esteem of dyslexic children. In addition, the dimensions of personal control also significantly correlated with self-esteem of children. The $r$ value of 0.557 indicates a stronger relationship between the dimensions of personal control and self-esteem of dyslexic children.

This finding is consistent with the findings Natale et al. (2009). Natale et al. (2009) found that parents who have a child diagnosed as having learning difficulties, disorders of attention deficit hyperactivity disorder or who receive special education services have a high tendency to attribute the success of academic or behavior to external cause such as the fate of the failures attributable to causes internal lack of ability or other characteristics associated with child (Himelstein, Graham \& Weiner, 1991; Johnston et al., 1998; Johnston \& Freeman, 1997; Pearl \& Bryan, 1982; Tollison et al., 1987). The results showed that parents or guardians of children with dyslexia to attribute the cause of dyslexia is happening to their child to external factors and personal factors. Attribution to the external factors include parents attribute the cause of dyslexia occur in the environment, such as fate or destiny while personal factors are more internal. Personal factors or personal control over emphasize the feeling of an individual who feels himself able to control the things attributed to him.

This finding is also consistent with the findings of Dura-Vil, Dein and Hodes (2010). The results of their study found that religious or spiritual beliefs have an important role in influencing the level of understanding of parents of children with intellectual disabilities and parents coping. It shows parents attribute the things that happen to their children due to external factors (Dura-Vil et al., 2010). According to Heider, someone makes two types of attribution, namely (1) internal attribution where someone is behaving themselves because factors like behaviors, and personality traits and (2) a second, external attribution where someone behaves caused by certain situations.

\section{Attributional Style Parents Have an Influence on The Self-Esteem of Children With Dyslexia}

The results of multiple regression analysis showed that the attribution style of parents in the form of personal control have a stronger influence on the self-esteem of children with dyslexia, R2 $=0.363$ compared with attribution style of parents in the form of external control, R2 $=0.166$. This means that changes in the dimensions of personal control attribution style parents bring the impact of changes on the level of self-esteem of dyslexic children by $36.3 \%$ compared with the dimensions of external control that just affect change by $16.6 \%$ to a level of self-esteem of dyslexic children. It also shows the style of attribution parents have an influence on the self-esteem of dyslexic children. Therefore, the alternative hypothesis constructed accepted.

Low levels of self-esteem can be perceived as one aspect of emotional problems and other problems that correlate with dyslexia (Humphrey \& Mullins, 2002). Harter, Whitesell and Junkin (1998) found that high school students who have learning disabilities reported that they feel inferior about their intellectual ability in general when compared with students who did not face the same problem. Self-esteem level of dyslexic children were influenced by the style of their parents or guardians attribute the disorder happened to their children. 
Attribution style parents also show parents how acceptance of the things that happen to their children in particular, dyslexia.

This situation can be explained by the context of the Asian community. Gupta and Singhal (2004) stated that cultural beliefs about the inability to play an important role in understanding how they perceive the situation experienced. For example, in India, disability is seen as a 'tragedy' with conditions 'better dead than incapable', then it is impossible for individuals with disabilities to be happy or enjoy a quality life (Chihiro, 2011). In addition, Ryan and Smith (1989) reported that ethnic Chinese parents tend to believe that American children's inability is the result of what you've done and avoid blame for causing the condition. Some people also blame their partner for the situation of children with disabilities (Chihiro, 2011). In Malaysia, children with dyslexia are considered as those with disabilities. Based on the study Chihiro (2011), researchers can conclude that Asian people with disabilities tend to attribute what happened to the children or themselves to external factors rather than internal. Unique perceptions about special needs children should influence and shape all aspects of pressure-related experience and acceptance of assistance (Ibrahim, 2006) in Chihiro (2011). In other words, how parents attribute the things that happen to their children, especially in the context of shaping the early experiences of dyslexia which affects the level of self-esteem among dyslexic children.

The results of this study can also be associated with the experience of mothers take care of dyslexic children in Malaysia. According to the study Noor Amiera et al. (2015) conducted in Malaysia, the majority of mothers of dyslexic children blame themselves at an early stage. They tend to blame themselves when they are not able to identify the first signs of their child's condition. They thought they were late in taking action against their dyslexic child in providing appropriate interventions. Some of these mothers do not know about dyslexia before. Therefore, they tend to attribute learning difficulties experienced by children as something related to internal factors such as effort and ability (Noor Amiera et al., 2015). This can affect his level of self-esteem as learning difficulties experienced by itself is not something that is related to our own efforts but his learning disorder. However, most of the mothers were eventually learnt to accept the situation of the child. This is because most of them believe that they have to have a child 'special'. The majority of these mothers can control and overcome negative feelings in themselves since they know that dyslexia is not experienced as severe when compared with disabilities or other disorders (Noor Amiera et al, 2015). When mothers to attribute what happened to his son to external factors and are capable of controlling the cause of dyslexia occur and try to control the outcome (of educational attainment of children), the self-esteem of children also increased in view of his mother and that her condition was not due to a lack of effort or ability itself but because learning disorders suffered.

\section{Parent - Child Relationship and Self-Esteem in Children with Dyslexia}

Given the relationship parent - child does not have a significant relationship with self-esteem of children with dyslexia, indirect, variable relations parents - children do not have any relation to the self-esteem of dyslexic children. It also shows that the parent - child relationship does not affect the self-esteem of dyslexic children. Therefore, an alternative hypothesis is rejected. Results of this study has many contradictions with the results of the previous studies. For example, studies Shehu, Zhilla and Dervishi (2015), which examines the impact of the quality of social relationships to the self-esteem of dyslexic children. The results of their study showed there was a positive association between social relationships and a healthy level of self-esteem among dyslexic children. 
In addition, unhealthy social relationships associated with the lower self-esteem in children (Shehu et al., 2015). Results of this study showed that the quality of social relationships such as relationship parent - child have an impact or effect on the level of self-esteem among children with dyslexia. In contrast to the Shehu and friends, in this study, there was no effect or a significant correlation between the relationship parents - children and the self-esteem of dyslexic children. This was probably due to the support-social support obtained by dyslexic children through sexual attachment to another. Social relationships with peers or with teachers also affect the self-esteem of dyslexic children. In the school environment also plays an important role in increasing the level of self-esteem among children with dyslexia.

To conclude, several studies have found a relationship between the child's self-esteem and the quality of parent-child relationship. The result of current study adds to the growing literature on the importance of parental support in influencing one's self-esteem in children with dyslexia.

\section{References}

American Psychiatric Association (2013). Diagnostic and Statistical Manual of Mental Disorders ( $5^{\text {th }}$ ed.). Washington, DC.

Chihiro, Y. (2011). Attribution for Maternal Stress in Children with Different Special Needs. Disertasi, National Institute of Education, Nanyang Technological University.

Durà-Vilà, G., Dein, S. \& Hodes, M. (2010). Children with intellectual disability: A gain not a loss: Parental beliefs and family life. Clinical Child Psychology and Psychiatry, 15(2) 171-184.

Folb, N. (2013). Dyslexic writers and the idea of authorship. Journal of Writing in Creative Practice, (5), 125-139.

Gupta, Ashum \& Singhal, N. (2004). Positive perceptions in parents of children with disabilities. Asia Pacific Disability Rehabilitation Journal. (15), 21-34.

Harter, S., Whitesell, N.R., Junkin, L.J. (1998). Similarities and differences in domain specific and global self-evaluations of learning disabled, behaviourally disordered, and typically achieving adolescents. American Educational Research Journal, 35(4), 653-680.

Humphrey, N., \& Mullins, P. M. (2002). Self-concept and self-esteem in developmental dyslexia. Journal of Research in Special Education Needs, 2 (2).doi:10.1111/j.14713802.2002.00163.

Heyman, W. (2000), "The Self-Perception of a Learning Disability and its relationship to Academic Self-concept and Self-esteem”. Journal of Learning Disabilities, (23), 473475.

Himelstein, S., Graham, S., \& Weiner, B. (1991). An attributional analysis of maternal beliefs about the importance of child-rearing practices. Child Development, (62), 301-310.

Johnston, C., Reynolds, S., Freeman, W.S., \& Geller, J. (1998). Assessing parent attributions for child behaviour using open-ended questions. Journal of Clinical Child Psychology, (27), 87-97.

Johnston, C., \& Freeman, W. (1997). Attributions for child behaviour in parents of children without behaviour disorder and children with attention deficit-hyperactivity disorder. Journal of Consulting and Clinical Psychology, (65), 636-645.

Natale, K., Aunola, K., \& Nurmi, J.-E. (2009). Children's school performance and their parents' causal attributions to ability and effort: A longitudinal study. Journal of Applied Developmental Psychology. 30 (1), 14-22. 
Noor Amiera Alias, Akehsan Dahlan \& Syamsul Anwar Sultan Ibrahim. (2015). Mothers' Experiences of Parenting A Child with Dyslexia At A Dyslexia Centre In Malaysia. Jurnal Teknologi, 77(33), 17-26.

Pearl, R. (1982). LD children's attributions for success and failure. A replication with a labeled LD sample. Learning Disability Quarterly, 5, 173-176.

Rohaty Majzub. 2005. Dyslexia: Prevalence Diagnosis and Remediation. Pendidikan, J. Kanak-kanak, Simptom Disleksia. 30: 3-19.

Rosenberg, M., Schooler, C., \& Schoenbach, C. (1989). Self-esteem and adolescent problems: Modeling reciprocal effects. American Sociological Review, (54), 10041018.

Shehu, A., Zhilla, E. \& Dervishi, E. (2015). The Impact of The Quality Of Social Relationships On Self-Esteem Of Children With Dyslexia. European Scientific Journal, 11(7), 308-318.

Singer 2005 Singer, E. (2005). The strategies adopted by Dutch children with dyslexia to maintain their self-esteem when teased at school. Journal of Learning Disabilities, 38(5), 411-423.doi:10.1177/00222194050380050401

Tollison, P., Palmer, D. J., \& Stowe, M. L. (1987). Mothers' expectations, interaction, and achievement attributions for their learning disabled of normally achieving sons. The Journal of Special Education, (21), 83-93.

Weiner, B. (1985). An attributional theory of achievement motivation and emotion. Psychological Review, (92), 548-573.

Weiner, B. (1986). An attributional theory of achievement motivation and emotion, Psychological Review,92(4), 548-573.doi:10.1037/0033-295X.92.4.548

Weiner, B. (1992). Human motivation. Metaphors, theories, and research. Newbury Park, CA: Sage. 